\title{
The value of the nuclear power plant fleet in the German power market under the expansion of fluctuating renewables
}

\author{
Juha Teirilä* \\ Department of Economics, University of Oulu
}

Pentti Kaiteran katu 1, 90570 Oulu, Finland

\begin{abstract}
Flexibility of a conventional power plant fleet is becoming an increasingly valuable quality in several electricity markets due to growing solar and wind power supply. Nuclear power plants are not very flexible in terms of output, but their advantage is their low variable cost of generating electricity. Using a short-term techno-economic model which incorporates both the electricity and the balancing market, we examine quantitatively whether costs incurred by nuclear units' lower flexibility outweigh the low generation costs of nuclear power in the German power market, and investigate how this depends on the amount of fluctuating renewables. We show that, due to low negative prices stemming from inflexible baseload plants, balancing costs may increase rapidly with solar and wind power. Higher balancing and start-up costs arising from nuclear units in the fleet are still largely compensated by the nuclear units' lower generation costs, and it is not costefficient to decommission nuclear units in the near future. The results suggest that it would be economically beneficial to harness the full flexibility potential of nuclear plants and curtail excess solar and wind power or include those in the negative balancing reserve.
\end{abstract}

Keywords: flexibility, nuclear phase-out, balancing cost, start-up cost, economic curtailing, renewable energy

\footnotetext{
*Corresponding author

Email address: juha.teirila@oulu.fi (Juha Teirilä)
} 


\section{Introduction}

Increasing power supply from fluctuating weather-dependent renewables - solar and wind imposes new challenges on electrical power systems. Conventional power plants ${ }^{1}$ have to meet increasingly varying residual demand, and even those power plants, which are designed to provide fairly invariant baseload power, are facing times more frequently where they have to adjust their output power substantially (Schill (2014), Troy et al. (2010), Pérez-Arriaga and Batlle (2012)). Therefore, flexibility is becoming a more and more important characteristic for conventional power plant fleets (Denholm and Hand (2011), Huber et al. (2014), Kondziella and Bruckner (2016)). The flexibility of a power plant fleet can be defined as the fleet's ability to vary output and respond to rapidly varying and less predictable residual demand (Denholm and Hand (2011), Ma et al. (2013)). A single power plant's flexibility depends on its technical characteristics (ramping rate, minimum load, start-up time and cost, etc.). Besides that, also the plant's commercial commitments in other markets (such as forward or balancing market, or heat market for CHPs) may restrict its ability to adjust output in the short term.

Nuclear power plants provide a significant share of the baseload power in many countries. While having low variable costs, they are usually considered the most inflexible of all conventional power plant types. Comparing technical characteristics related to power plant flexibility, in particular start-up cost and ramping rate, reveals that nuclear units truly are outperformed by most conventional units. This is especially true for gas-fired and hydro units. The lack of flexibility partly explains why nuclear units are usually observed to generate electricity at the full rate (excluding maintenance breaks), even if the electricity price is very low or even negative. However, there may also be other reasons why nuclear units' output power is typically relatively invariant, for instance due to economic, legal, or habitual determinants (Cany et al. (2018), Ludwig et al. (2010), NEA (2011), Jenkins et al. (2018)).

The increasing need for flexible baseload power is a particularly timely issue in Germany. The German energy policy has favored renewables since 2000, resulting in a very fast adoption of different renewable energy sources. Solar and wind power generation in Germany grew from 9.6

\footnotetext{
${ }^{1}$ By conventional power plants, we mean nuclear, fossil fuel-fired, and hydro plants.
} 
TWh in 2000 to 116.7 TWh in 2016, an amount 12 times higher. The German target is to cover $40-45 \%$ of the gross electricity generation with renewables by 2025, and $55-60 \%$ by 2035 (32 $\%$ was covered in 2016). To achieve this ambitious goal, solar and wind energy have to increase by $50 \%$ from the year 2017 level by 2025 , and double the 2017 level by $2030 .^{2}$ At the same time, the German Federal Government has decided to decommission all nuclear power plants by 2022. Eight out of 17 reactors were closed soon after the Fukushima accident in 2011, and one in 2015. In 2017, there were still eight reactors online. Decommissioning all nuclear units in such a short time frame obviously has a significant impact on the flexibility and the costs of the German conventional power plant fleet.

In this paper, we quantitatively investigate the economic value of nuclear power plants in the German power market: does the relatively low flexibility of nuclear units incur such additional costs in the market which outweigh the benefits arising from the nuclear units' lower variable costs? Accounting for both the balancing market and the electricity market, we identify the main channels through which the inflexibility of nuclear units is reflected in power market costs and examine how these costs evolve under further expansion of weather-dependent fluctuating renewables. Specifically, we solve the hourly least-cost dispatch schedule (a.k.a. "the unit commitment problem") for a fleet which imitates German power plants in 2017, and for the corresponding fleet after the planned nuclear phase-out in 2022. We vary the amounts of intermittent solar and wind energy and compare incurring start-up, balancing, and generation costs. Our analysis is short-term in the sense that, in addition to changes in the nuclear power and renewables, we do not account for any other structural changes in the electricity market, such as changes in the power plant portfolio, fuel or carbon prices. Thus, the results should be interpreted as an isolated analysis of nuclear flexibility in the market, instead of a forecast of future price or cost development. ${ }^{3}$

A common method to examine the effects of fluctuating demand on a power plant fleet at a unit

\footnotetext{
${ }^{2}$ See BMWi (2017a) for the past development and BMWi (2017b) for the future electricity generation targets for the renewables.

${ }^{3}$ In the long run, increasing price volatility due to an increase in renewable supply may trigger the deployment of new technologies which exercise price arbitrage. Smoothing peaks and troughs in residual demand, this would mitigate the flexibility needs of the conventional power plants. These technologies include utility-scale electricity storages, demand response, sector coupling (co-optimizing electricity demand and supply in, for instance, electricity
} 
level is by using a model based on a non-convex dynamic optimization problem, which accounts for dynamic costs and constraints of the individual power plant units (start-up cost, minimum load, ramping rate, etc.). This kind of model is called a unit commitment model, since it resolves the unit-specific optimal - typically cost-minimizing - dispatch schedule. This approach is applied in several quantitative papers addressing integration costs of renewables. For example, Troy et al. (2010) examine the impact of increasing wind power on start-ups, cycling, and utilization of baseload units in the Irish electricity market. They find a significant impact but do not directly report the costs incurred. In a similar vein, Lew et al. (2013) investigate in detail the impact of increasing solar and wind power in the Western US, and report impacts on cycling costs (resulting from wear and tear and additional fuel costs) and emissions of the conventional power plants. They find that the cost of increased cycling is relatively small when compared to, for example, fuel costs. Their study is rather a technical cost analysis from the power plants perspective than a market-level study from the electricity buyers' perspective. Using the same simulation tool and the subset of the market area, Palchak and Denholm (2014) complement the study of Lew et al. (2013) by examining the sensitivity of costs and emissions to a lower minimum load of coal plants. They report implications of increased coal plant flexibility on market prices and coal plant revenues. Schill et al. (2017) provide a similar analysis in the German market with a focus on start-up costs and their development with increasing market shares of fluctuating renewables. The study compares alternative generator portfolios having different system-level flexibilities. Our paper complements this analysis by adding an opportunity-cost-based balancing market to the unit commitment model. We confirm many of the findings in Schill et al. (2017), though accounting for commitments in the balancing market leads to a slightly different number of start-ups in our model. Furthermore, neither Schill et al. (2017) or Palchak and Denholm (2014) account for negative prices, which are an important element in our analysis.

A recent paper by Kopiske et al. (2017) is particularly close to our study. Using a unit commitment model with endogenous prices both for the electricity and the balancing power, the authors compare the performance of the 2014 German fleet with the planned future fleet in 2035, with

generation, transport and heating sectors), or more generally power-to-X technologies (power-to-heat, gas, hydrogen, etc.). See Lund et al. (2015) for a review. 
regard to the increased market share of variable renewables expected for 2035. They quantify the contribution of lower minimum load and higher ramping rate to the power plants' revenues. Using a similar approach but somewhat different methodology and data, our study sharpens their analysis by focusing on the impact of the nuclear phase-out and the cost trade-off between lower nuclear generation costs and the costs arising from the units' lower flexibility. Additionally, we also provide a detailed cost breakdown for different levels of fluctuating renewables. Regarding the important role of the balancing market in integration costs, and as a main channel for inflexibility of a conventional power plant fleet turning into costs, our results are well in line with Kopiske et al. (2017).

Our paper further contributes to an important strand of literature which addresses the effects of the German nuclear phase-out on the electricity market. Using different time frames, phaseout schedules, and methods, several studies analyze implications of the phase-out on capacities, generation of the units, net exports, prices, $\mathrm{CO}_{2}$ emissions, security of supply, congestions, etc. Fursch et al. (2012), Bruninx et al. (2013), and Kunz and Weigt (2014) provide good reviews of this literature. The majority of these studies come to similar conclusions; when nuclear power plants leave the market, fossil fuel-fired generation increases, net exports decrease, and wholesale prices and emissions increase in short-term due to the merit order effect but decrease in the longer term, when the share of zero variable cost renewables grows. The estimates for the short-term price increments vary from 5 to 13 EUR/MWh, depending on the time frames and model assumptions used (Lechtenböhmer and Samadi (2013), Kunz and Weigt (2014)). We extend this literature by highlighting the impact of the nuclear phase-out on the balancing costs, showing that low flexibility of baseload power can increase balancing costs considerably if the share of renewables is high enough, even if the amount of the procured balancing power does not grow. This is driven by price effects. We illustrate how balancing costs depend on the share of renewables, and how they should be accounted for when assessing the proper timing and the total costs of the nuclear phase-out.

In what follows, we start by discussing briefly the technical flexibility of the German nuclear power plants in Section 2. Section 3 presents our modeling approach, and Section 4 describes the data used in the simulations. We present and discuss the results of our analysis in Section 5, and 
Section 6 concludes.

\section{Nuclear power plant flexibility}

When most German nuclear power plants were built in the 1970s and the 1980s, it was anticipated that nuclear plants will soon generate a remarkable share of the electricity consumed in Germany. Therefore, German nuclear power plants were originally designed to be capable of operating in a flexible load following mode (IAEA (2018), p. 107). Eventually, the most ambitious nuclear penetration level targets were not realized, and thereby, the German nuclear power plants have mostly been running in a baseload mode with rare variations in the output power. However, the flexibility already built-in in the German nuclear power plants has recently - due to increasing renewables - become a valuable characteristic for power plants anew.

IAEA (2018) (Annex I) and Ludwig et al. (2010) list some requirements that German nuclear power plants had to meet in their qualification tests in the commissioning phase. For instance, one requirement was a change in the plant's output power at the rate of $2-10 \%$ of its nominal power within a minute (faster in a smaller power range close to their maximum power, and slower in their full generation range). Furthermore, it was required that the plant is able to cycle from full power to $80 \%$ and back 100000 times in its entire operating lifetime (about 40 years), to $60 \%$ and back 15000 times, and to $40 \%$ and back 12000 times.

If the electricity price is negative, it is economically rational to ramp all electricity generation down to the minimum level (ignoring dynamic constraints, commitments in other markets, strategic behaviour, etc.). Hence, power plants' generation decisions during negative-price periods reveal something about their true flexibility. In 2017, the electricity price was negative in Germany (in EEX day-ahead market) at 146 hours. Figure 1 shows the hourly average output power of three German nuclear power plants (three other online units are left out for clarity, their output follows similar patterns as those in the figure) on a seven-day period when the price was negative or very low for 19 hours (-74.92 EUR/MWh at the minimum). Different generation strategies can be identified in the figure. When the price turned negative, Neckarwestheim 2 lowered its output power by about two thirds, Isar 2 by one third, whereas Gundremmingen $\mathrm{C}$ continued generating at full rate. Unlike the other units, Isar 2 varied its output power frequently during the entire time period. 
Outside the larger ramps, the other two nuclear units generated smoothly at a constant power rate. Reductions in Isar 2's output coincide with the times when negative secondary balancing power was activated suggesting that it may have been providing part of the required negative balancing power. IAEA (2018) (p. 116 - 128) describes how German power plants are equipped with advanced automatic control systems which can be used to provide primary and secondary frequency control when requested by the grid operator. In 2018, $500 \mathrm{MW}$ of nuclear power was pre-qualified for the primary reserve in Germany, $420 \mathrm{MW}$ for the secondary, and $2040 \mathrm{MW}$ for the minute reserve (Regelleistung.net (2017a)). In France and Slovakia, nuclear units participate in the primary and secondary reserve on a regular basis (Bruynooghe et al. (2010), NEA (2011)).

Similar behaviour can also be observed during other time periods with negative prices. For example, at the end of December 2017, the price was negative throughout several shorter time periods. During this time, some units ramped up from the minimum level to the maximum load, even if the price was positive only for a few hours. According to IAEA (2018) (p.128), the minimum load for the German nuclear reactors used in specific cases, such as negative market prices, is 20 $\%$ for the pre-Konvoi type reactors (Brokdorf and Grohnde) and $30 \%$ for Philippsburg 2 and the three Konvoi reactors (Emsland, Isar 2, and Neckarwestheim 2).

In France, running nuclear units in a load following mode has a long history. According to Cany et al. (2018), the minimum load of French PWR reactors is 20 - $30 \%$, and theoretically, they are able to ramp between the minimum load and maximum load in 15 minutes ( $5 \%$ of nominal power per minute). Cany et al. (2018) present data of a nuclear unit cycling twice a day, first from the maximum load to a $45 \%$ level and back, and then to a $23 \%$ level and back to the maximum. Most German and French nuclear reactors are based on the same technology (PWR, Pressurized Water Reactor).

\section{Methodology}

In this section, we first define the equilibrium condition in the electricity grid, and describe how we derive from that the residual demand which has to be met by the conventional generators in the spot market, given the renewable supply. Then, we present our modeling approach for the 
Figure 1: The hourly output power of three German nuclear units (Neckarwestheim 2 owned by EnBW, Isar 2 by PreussenElektra, and Gundremmingen $\mathrm{C}$ by RWE), the activated negative secondary reserve, and the electricity price (right axis) 27.4 - 3.5 2017. Sources: ENTSO-E (2017e) for generation, ENTSO-E (2017d) for activated balancing power, and EPEX (2017a) for prices.

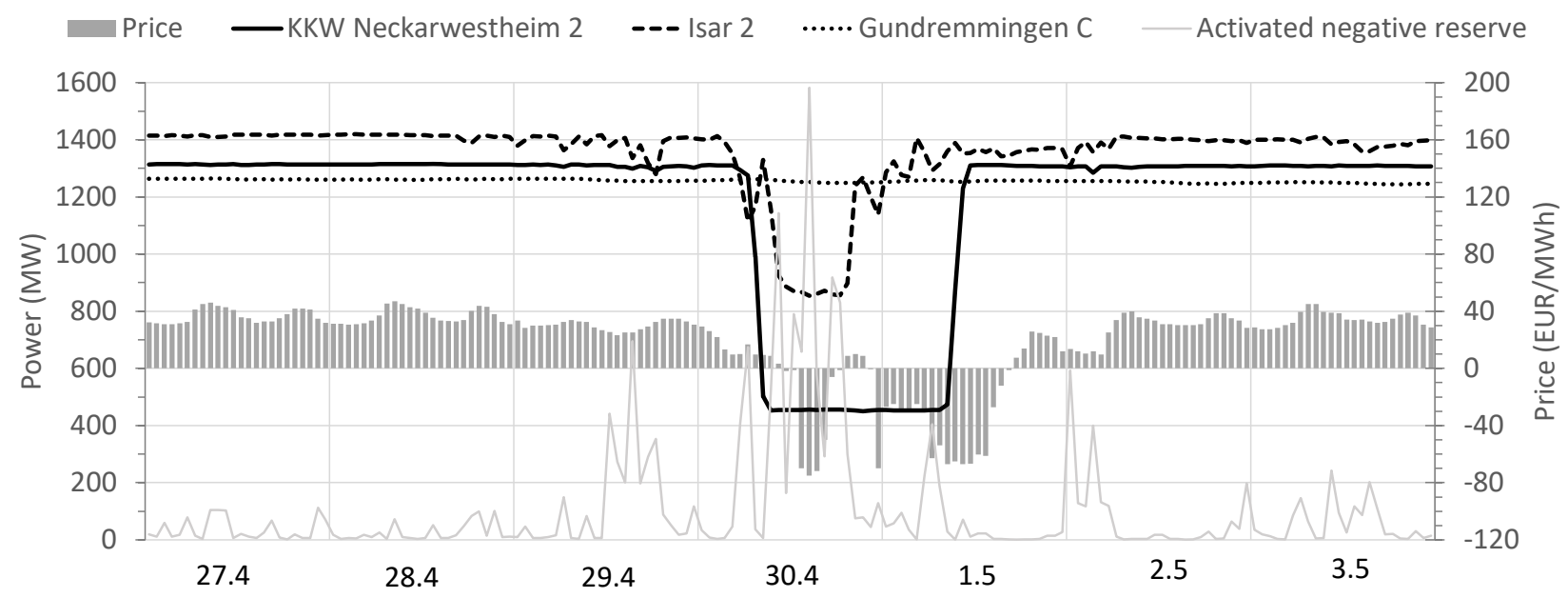

costs and commitments in the balancing market. These commitments have an impact on the spot market, which we describe in the end of the section.

\subsection{Residual demand}

All generated electricity that is fed into the grid has to be consumed at all times. We use hourly resolution, so the following balance of physical electricity flow in the grid has to hold for all hours $h:$

$$
T C_{h}+N X_{h}=Q_{h}^{\text {conv }}+Q_{h}^{\text {pump }}+Q_{h}^{\text {solar }}+Q_{h}^{\text {wind }}+Q_{h}^{\text {rest }},
$$

where $T C_{h}$ is the total domestic electricity consumption in Germany (including both the spot market demand and the net balancing energy demand, but net of consumption by pumped hydro storages), and $N X_{h}$ is the net exports in the German area (exports less imports across all interconnectors). On the supply (right-hand) side of (1), $Q_{h}^{\text {conv }}$ is the total generation of all conventional power plants (nuclear, lignite, hard coal, and gas), $Q_{h}^{\text {pump }}$ is the net supply (generation less consumption) of pumped hydro storages, $Q_{h}^{\text {solar }}$ and $Q_{h}^{\text {wind }}$ are aggregated generations of solar and wind power plants, respectively, and $Q_{h}^{\text {rest }}$ denotes the electricity generation of all other power plants (such as biomass, hydro, and oil-fired plants). 
The total consumption $\left(T C_{h}\right)$, the solar and wind power supply $\left(Q_{h}^{\text {solar }}\right.$ and $\left.Q_{h}^{\text {wind }}\right)$, and the net supply from the pumped hydro storages $\left(Q_{h}^{\text {pump }}\right)$ and other smaller plants $\left(Q_{h}^{\text {rest }}\right)$ are assumed to be exogenous in the model and independent of each other. ${ }^{4}$ Instead, imports and exports are typically quite responsive to changes in domestic solar and wind power supply (via price differences). Consequently, we assume that the net exports depend on the domestic wind and solar power linearly as follows: ${ }^{5}$

$$
N X_{h}=a+b\left(Q_{h}^{\text {solar }}+Q_{h}^{\text {wind }}\right)+\epsilon_{h},
$$

where $a, b>0$ are parameters, and $\epsilon_{h}$ is the deviation from the purely linear relationship. Hourly net exports are limited by the aggregated interconnector capacities: $-I^{\max } \leq N X_{h} \leq X^{\max }$, where $I^{\max }$ is the maximum import capacity, and $X^{\max }$ is the maximum export capacity for the entire country. Accordingly, each additional MWh of solar or wind energy increases net exports by $b$ MWh (by increasing exports and replacing part of imports). Our estimate for $b$ is 0.176 for Germany (see Section 4). Thus, of each new domestically generated $1 \mathrm{MW}$ of solar and wind power, 0.176 MW is absorbed abroad (0.081 MW is exported and 0.095 MW of imports is replaced). The remaining $0.824 \mathrm{MW}$ replace other domestic generation. Thus, interconnectors mitigate the flexibility needs of conventional power plants dampening the fluctuation of their residual demand.

The final generation amount of conventional power plants, $Q_{h}^{c o n v}$, is determined in two subse-

\footnotetext{
${ }^{4}$ German generation data by production type (ENTSO-E (2017b)) reveals that pumped hydro storages typically generate (and consume) following a fairly regular diurnal pattern throughout the year. Their generation amounts are not significantly correlated with solar or wind power supply; pumped hydro storages seem to make profits mostly from diurnal price differences (which account for daily sunshine) rather than, for instance, variations in wind power supply. However, growing solar and wind power supply likely increase price volatility in the future, and pumped hydro storages may then alter their strategy and start following price changes more closely. This dampens the residual demand and mitigates the flexibility needs of the conventional fleet. Biomass, (run-of-river) hydro, and oil-fired units are often "must-run" units which are run when needed - independent of the market price and other generation. Solar and wind power supply are privileged in the grid, and exogenous by nature.

${ }^{5}$ A simple correlation analysis with the year 2017 data for the variables in Equation (1) shows that both exports and imports are highly correlated with the aggregated solar and wind power (Pearson correlation coefficient $\rho=0.61$ for the net exports and the aggregated solar and wind power). Imports decrease $(\rho=-0.64)$ and exports increase ( $\rho=0.40)$ with increasing solar and wind.
} 
quent markets. First, in the day-ahead market (called "spot market" below), the initial dispatch schedule is resolved based on forecast consumption and solar and wind power supply. In the second stage, forecast errors and other deviations from the spot market schedule (for example, unplanned outages) are balanced in the balancing market. ${ }^{6}$ Thus, the total generation of conventional power plants is the sum of the quantity they sell in the spot market, $S_{h}^{c o n v}$, and the adjustments based on balancing needs:

$$
Q_{h}^{\text {conv }}=S_{h}^{c o n v}+B P_{h}^{c o n v}
$$

where $B P_{h}^{\text {conv }}$ is the activated net (positive and negative) balancing power delivered by the conventional generators.

In our simulations below, we scale the realized amounts of solar and wind power $\left(Q_{h}^{\text {solar }}\right.$ and $\left.Q_{h}^{\text {wind }}\right)$ by arbitrary amounts, while keeping the other hourly exogenous supply $\left(Q_{h}^{\text {pump }}, Q_{h}^{\text {solar }}, Q_{h}^{\text {wind }}\right.$ and $Q_{h}^{r e s t}$ ) and the consumption $T C_{h}$ invariant. The actual generation required from the conventional power plants, $Q_{h}^{\text {conv }}$, can then be solved from Equations (1) and (2) and the corresponding residual demand in the spot market, $S_{h}^{\text {conv }}$, from Equation (3). The residual demand varies across hours, but is assumed to be fully inelastic within each hour.

Before the trade in the spot market takes place, the balancing commitments are resolved in the balancing market, which is described in detail in the next section.

\subsection{Balancing market}

We assume that all conventional generating units participate in the balancing market. In Germany, the balancing market consists of the primary, secondary, and the minute control reserve. The three reserve types are mainly distinguished by how fast the balancing power needs to be activated. We abstract from the primary reserve ${ }^{7}$ and model the secondary and the minute reserve

\footnotetext{
${ }^{6} \mathrm{We}$ abstract from the intraday market, since most trading in Germany is done in the day-ahead market (in 2010 - 2016, the traded volume in the EPEX intraday market was about $10 \%$ of the day-ahead market volume (BNetzA (2017))). We also ignore forward and bilateral contracts for simplicity.

${ }^{7}$ Power changes required from the units in the primary reserve are small and can be offered by most conventional units. Up and down adjustments typically offset each other during the contract period (one week), and there are no separate positive and negative reserves. Therefore, it is likely that the primary reserve cost is neither affected by
} 
separately. We consider only the "spinning reserve", so we assume that the units selected for the reserve have to be running at least at the minimum load for the entire balancing power contract period.

Units for the secondary and the minute reserve are procured in auctions, wherein generating units submit two prices with the capacity quantity which they offer for the reserve - a capacity price and an energy price (separately for the positive and negative reserve). Units are selected for the reserve starting from the lowest capacity price offer through higher ones, until the desired capacity amount is reached. So, the capacity price offers alone determine the selected units. When balancing power is needed, the units selected in the reserve are activated based on their energy price offers - the lowest offer first, until enough power is activated. Unlike in the spot market, the units in the reserve are paid for according to their individual offers ("pay-as-bid" scheme). In our analysis, we assume that the procured capacity and activated balancing power are the same as what was realized in 2017 (see Section 4.4).

There are $J$ conventional generating units participating in the spot market and the balancing market. A generating unit $j$ can offer at most a capacity $K_{j}^{r e s}$ for the balancing reserve:

$$
K_{j}^{r e s}=\min \left\{r r_{j} \times T^{a c t} \times K_{j}^{\max }, \quad K_{j}^{\max }-K_{j}^{\min }\right\},
$$

where $r r_{j}$ is the maximum ramping rate (\% of nominal power / minute), $T^{a c t}$ is the longest allowed time interval between the reserve request and the reserve activation in minutes ( 5 minutes in the secondary reserve and 15 minutes in the minute reserve), $K_{j}^{\max }$ is the nominal power (maximum load), and $K_{j}^{m i n}$ is the minimum load of the unit $j$.

We assume that the units' bids in the balancing market are based on their opportunity costs in the spot market (following, e.g., Müsgens et al. (2014) and Hirth and Ziegenhagen (2015)). Thus, for the positive reserve, if a unit is profitable in the spot market (the unit's variable cost is lower than the price), it submits a capacity price bid $c b_{j}^{+}$which is equal to the profit the unit loses for not being able to generate at full rate as it otherwise would (to be able to ramp up if requested by the balancing operator). A unit which is not profitable in the spot market (the unit's variable cost is

variations in the solar and wind power, nor does it change with the conventional power plant portfolio as much as, for instance, the secondary reserve cost. 
higher than the price) bids the price which equals its losses from generating the minimum amount to keep it available to ramp up if needed. Formally,

$$
c b_{j}^{+}=\left\{\begin{array}{l}
\bar{p}-V C_{j}, \quad \text { if } V C_{j} \leq \bar{p} \\
\left(V C_{j}-\bar{p}\right) \times \frac{K_{j}^{\min }}{K_{j}^{r e s}}, \quad \text { if } V C_{j}>\bar{p}
\end{array},\right.
$$

where $V C_{j}$ is the variable cost of a unit $j$, and $\bar{p}$ is the average spot market price during the time period when the balancing power offer is valid. The energy price bids for the positive reserve equal the variable cost of increasing the electricity supply: $e b_{j}^{+}=V C_{j}$.

Correspondingly, units submit the following capacity price bids for the negative reserve:

$$
c b_{j}^{-}=\left\{\begin{array}{l}
0, \quad \text { if } V C_{j} \leq \bar{p} \\
\left(V C_{j}-\bar{p}\right) \times \frac{K_{j}^{\text {min }}+K_{j}^{r e s}}{K_{j}^{r e s}}, \quad \text { if } V C_{j}>\bar{p}
\end{array} .\right.
$$

In the negative reserve, if the unit is profitable in the spot market, its energy bid equals the lost profit if required to ramp down. Otherwise, the energy bid is zero:

$$
e b_{j}^{-}=\left\{\begin{array}{l}
\bar{p}-V C_{j}, \quad \text { if } V C_{j} \leq \bar{p} \\
0, \quad \text { if } V C_{j}>\bar{p}
\end{array} .\right.
$$

Balancing market bids are submitted and commitments resolved before the spot market trade for the same time period takes place. If a unit is selected for the reserve in the balancing market, it takes this commitment into account in its spot market bids. Specifically, if a unit $j$ is selected for the positive reserve, it has to generate at least the minimum load and be available for a possible upward balancing power activation call: $K_{j}^{\min } \leq q_{j h} \leq K_{j}^{\max }-K_{j}^{r e s}$, where $q_{j h}$ is the generation amount of unit $j$ at hour $h$. Similarly, the unit selected for the negative reserve has to be available for a possible downward power activation: $K_{j}^{\min }+K_{j}^{\text {res }} \leq q_{j h} \leq K_{j}^{\max }$.

The capacity payment for a single unit accepted for the positive reserve is $c b_{j}^{+} \times K_{j}^{r e s}$, and the total positive capacity payment in the market $\left(C P^{+}\right)$is the sum of the payments for all units selected for the positive reserve. The same applies for the negative reserve $\left(C P^{-}\right)$. Energy payments are the product of the energy bids $\left(e b_{j}^{+}\right.$and $\left.e b_{j}^{-}\right)$and the activated power for each unit (from 0 to $K_{j}^{r e s}$ ), 
totaling $E P^{+}$and $E P^{-}$for the positive and negative reserve, correspondingly. The total cost in the balancing market is the sum of the capacity payments and the energy payments:

$$
\text { balancing cost }=C P^{+}+C P^{-}+E P^{+}+E P^{-} \text {. }
$$

\subsection{Spot market}

The spot market takes place after the balancing commitments have been resolved in the balancing market. $J$ conventional generating units together supply the residual demand $S_{h}^{c o n v}$ in Equation (3) in the spot market. $H$ hours are considered. Hourly electricity quantities for each generating unit, $q_{j h} \forall j \in\{1 . . J\}, h \in\{1 . . H\}$, are selected so that the costs are minimized: ${ }^{8}$

$$
\begin{gathered}
\min _{q_{j h}} \sum_{h=1}^{H} \sum_{j=1}^{J}\left(V C_{j} \times q_{j h}+S C_{j h}\right), \quad \text { s.t. } \\
\sum_{j=1}^{J} q_{j h}=S_{h}^{\text {conv }} \quad \forall h \in\{1 . . H\}, \\
S C_{j h}=\left\{\begin{array}{l}
S C_{j}, \quad \text { if } \quad q_{j, h-1}=0 \wedge q_{j h}>0 \\
0, \text { otherwise }
\end{array}\right. \\
q_{j h}=0 \quad \text { or } \quad q_{j h}^{\text {min }} \leq q_{j h} \leq q_{j h}^{\max },
\end{gathered}
$$

where $S C_{j h}$ is the start-up cost of a unit $j$ (positive only if the unit $j$ needs to be started up at hour $h)$. If unit $j$ is running $\left(q_{j h}>0\right)$, it is constrained to generate electricity in a specific range, from $q_{j h}^{\min }$ to $q_{j h}^{\max }$. These unit- and hour-specific constraints are based on technical restrictions and commitments in the balancing market as described in the previous section. ${ }^{9}$ Some further implementation details of the spot market model are described in Appendix A.

\footnotetext{
${ }^{8}$ In reality, firms often behave strategically in the electricity market, so that the actual costs deviate from the leastcost solution, and the market price is higher than the marginal generation cost (see, e.g., Newbery and Greve (2017) for a discussion about price mark-ups in the electricity market, and how to model them). Since our variable cost estimates are based on observed data, they may include some price mark-ups over the true marginal costs.

${ }^{9} \mathrm{We}$ ignore ramping costs in the cost minimization problem, since they are typically quite small when compared to other cost components. For example, Lew et al. (2013) find that when renewables increase from zero up to $33 \%$ in the Western U.S., the share of ramping costs (resulting from wear and tear) of total system production costs increases from $0.1-0.4 \%$ to $0.4-1.3 \%$, which are approximately $8-21 \%$ of the start-up costs. However, we report some ramping cost estimates in Table 1 which are calculated ex-post.
} 
In the results section below, we report the results separately using the following spot market cost components:

$$
\begin{aligned}
\text { generation cost } & =\sum_{h=1}^{H} \sum_{j=1}^{J} V C_{j} \times q_{j h}, \\
\text { start-up cost } & =\sum_{h=1}^{H} \sum_{j=1}^{J} S C_{j h},
\end{aligned}
$$

where $q_{j h}$ is the solution for the minimization problem (6). ${ }^{10}$

\section{Data}

We use the year 2017 as the reference point in our analysis and calibrate our model using demand and generation data from the German electricity market (EEX) in that year. We obtain total demand, aggregated solar and wind power generation, pumped hydro storage net supply, cross-border flows, procured balancing capacity, and activated balancing power from the ENTSOE Transparency Platform (see ENTSO-E (2017a) - ENTSO-E (2017d)), and historical electricity prices from EPEX SPOT (EPEX (2017a)). Using this data, the OLS estimation for Equation (2) gives $a=2072 \mathrm{MW}$ and $b=0.176$ with a standard error of 0.0025 . Thus, on average, of each additional MWh of solar or wind power, $18 \%$ are absorbed by interconnectors as long as their capacity is not binding. There are several reasons for why the total net export flow in a bidding area is typically much less than the sum of nominal export capacities of all interconnectors together, even if the market price is very low or high (see, e.g., Turvey (2006)). Therefore, we use the maximum realized net export in $2017(15 \mathrm{GW})$ as an upper bound for the net export in the German market.

For the individual generation units' hourly generation, we use data from the ENTSO-E website (ENTSO-E (2017e)). Generating units with less capacity than $100 \mathrm{MW}$ are not required to publish

\footnotetext{
${ }^{10}$ Note that - as in the real world - the balancing market and the spot market are cleared sequentially; when placing bids in the balancing market, the units do not take directly into account how this affects their position in the spot market. But, since the bids are based on opportunity costs and the price expectations are rational, the units are indifferent about which market to participate in.
} 
their hourly generation, and thus not included in our data. These omitted units are mostly gas-fired. We also exclude oil-fired units from our conventional power plant fleet since they are typically used in different industrial processes, and sell to the market only if the demand is exceptionally high. In total, we end up having 145 conventional generating units (69988 MW) in our simulation model.

To estimate generator costs, technical constraints, and the electricity price given a generator portfolio, we use historical data from the German electricity market. Our estimation methods are described in detail in the supplementary material, C.1.

An important assumption we make is that the amount of procured and activated balancing power stays constant, even if the amount of solar and wind power increases. ${ }^{11}$ It is often argued that supply prediction errors - and thus, the balancing power needs - scale up proportionally to an increasing amount of weather-dependent power supply (Holttinen et al. (2011)). However, the German data shows that at least so far, the activated balancing power has not yet increased with solar and wind power. Hirth and Ziegenhagen (2015), and Ocker and Ehrhart (2017) provide insight into and possible explanations for this "German paradox". Nevertheless, increasing balancing power needs in the future can certainly not be ruled out. Therefore, our results for the balancing market costs should be interpreted as rather conservative estimates, representing the lower bound of these costs. On the other hand, as we assume for reasons of simplicity that all balancing power is provided by nuclear and fossil fuel-fired units, balancing power provided by, for instance, hydro plants is omitted. This approach can potentially inflate our cost estimates.

\section{Results and discussion}

\subsection{Experimental set-up}

The main part of the analysis compares two fleets, the "2017 fleet", which consists of 145 nuclear, lignite, hard coal, and gas units which were available for most of the year in 2017 (see Section 4), and the "No nuclear" fleet, which is the same as the "2017 fleet", excluding the (eight

\footnotetext{
${ }^{11}$ We use the procured capacity and the activated energy in 2017 for all future values, as well. This data is available in ENTSO-E (2017d), with a more detailed coverage - for instance, anonymised bids - being available in Regelleistung.net (2017b).
} 
remaining) nuclear units. We focus on start-up, balancing, and generation costs, and compare how they evolve in different fleets when the amount of solar and wind energy in the grid increases from the level in 2017. We restrict the growth to a $50 \%$ increase in solar and wind supply, planned to be reached by 2025 . For any point further in the future, the German power market is likely to experience bigger structural changes affecting the power plant portfolio and the market structure considerably (for instance, increasing large-scale storage, more interconnector capacity, etc.). To isolate the impact of nuclear power and its phase-out, we omit any other long-term changes in the market. We also abstract from potential local congestions in the grid due to high influx of solar or wind power supply.

To better understand what is going on behind the scenes, we first present the results for each cost component separately, using three representative weeks: one with an exceptionally low, one with a medium, and one with an exceptionally high residual demand. After that, we report the main results based on simulations for an entire year. Figure 2 shows the residual demands in the three representative weeks we selected from the data realized in 2017 . We selected the two extreme weeks by first finding those hours in which the residual demand was among the highest (lowest) in 2017. Then, we picked a week which contained one of those extreme hours, while at the same time having a residual demand close to the annual average in the beginning and the end of the week. This approach captures the required ramping and start-ups from the average dispatch schedule to the extreme levels and back, and allows for composing different annual profiles by placing the representative weeks consecutively, with varying proportions of extreme weeks. The medium demand week is selected to contain only the most commonly occurring residual demand values.

The residual demand is the total demand in the market less the renewable supply. For example, the low residual demand week is a combination of low total demand, and high solar and wind supply. Therefore, the effect of increasing renewables is much larger in the low demand week than in the high demand week, wherein the solar and wind supply are initially low. This is also reflected in our results; the differences are typically largest in the low demand week. 
Figure 2: Hourly time series of realized residual demands faced by the conventional power plants in the three representative weeks (solid lines) and two simulated time series with higher solar and wind penetration (dashed lines). The high demand week was 21.1 - 27.1, the medium demand week $9.10-15.10$, and the low demand week $27.4-3.5$ in 2017.)

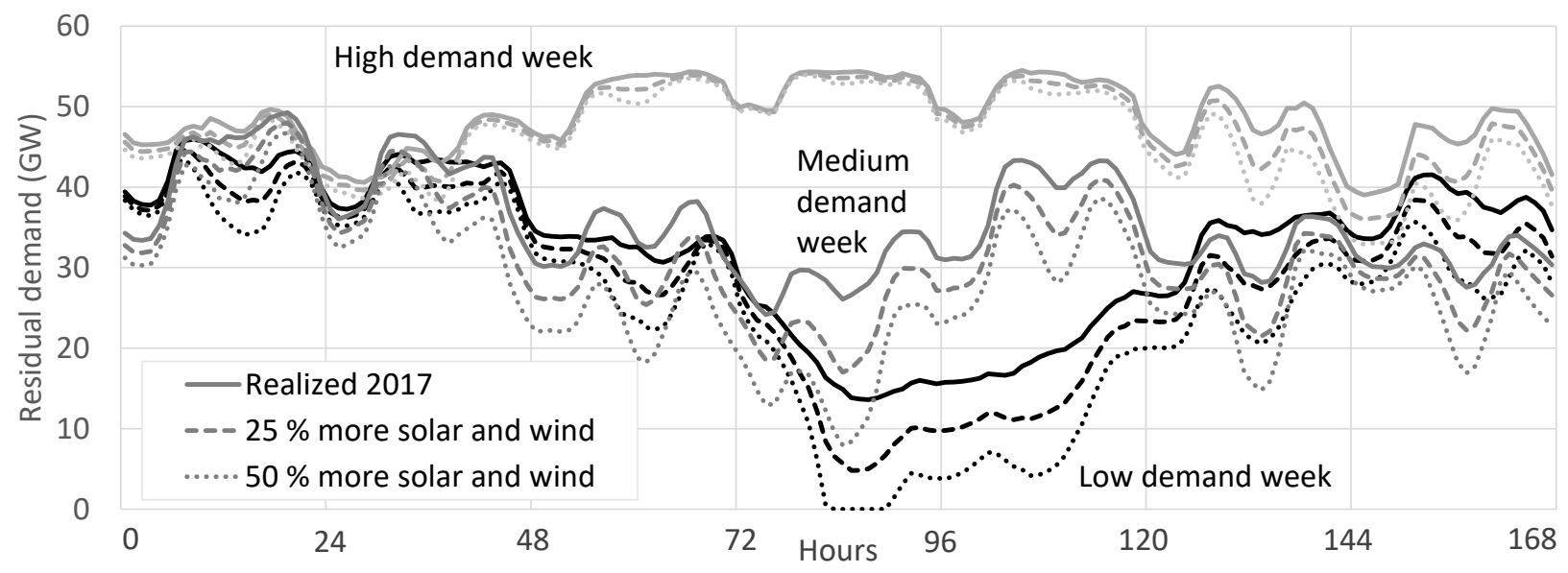

\subsection{Start-up costs}

The cost-minimizing number of start-ups in the fleet depends on several things, for instance, the variation in the residual demand met by the power plants, the technical and commercial characteristics of the plants, and the plants' commitments in other markets. Figure 3 shows the simulated number of start-ups in the two power plant fleets when solar and wind power supply increase up to $50 \%$ in the low demand week. Interestingly, the start-ups do not increase steadily with the fluctuating renewables as, perhaps, one would expect. ${ }^{12}$ Instead, in the "2017 fleet", the start-ups rather decrease when there is more solar and wind power. This is because at the low solar and wind penetration level, nuclear and lignite units compose a large share of the spinning balancing power reserve, and therefore they cannot be shut down. When renewables increase, gas units take over in the balancing market (see Figure 5), and shutting gas units down is not possible in a large scale. Thus, even though the start-ups increase for the low marginal cost units (here: nuclear and hard coal), they decrease by a larger amount for the other units (lignite and gas). The same logic

\footnotetext{
${ }^{12}$ For example, Schill et al. (2017) find that the start-ups in Germany will decrease with more renewables, but this is because they assume a more flexible power plant fleet in the future. If the fleet remains the same, the number of start-ups strongly increases in their study.
} 
applies to the "No nuclear" fleet.

Figure 3: Number of start-ups by fuel type in the low demand week with different power plant fleets.

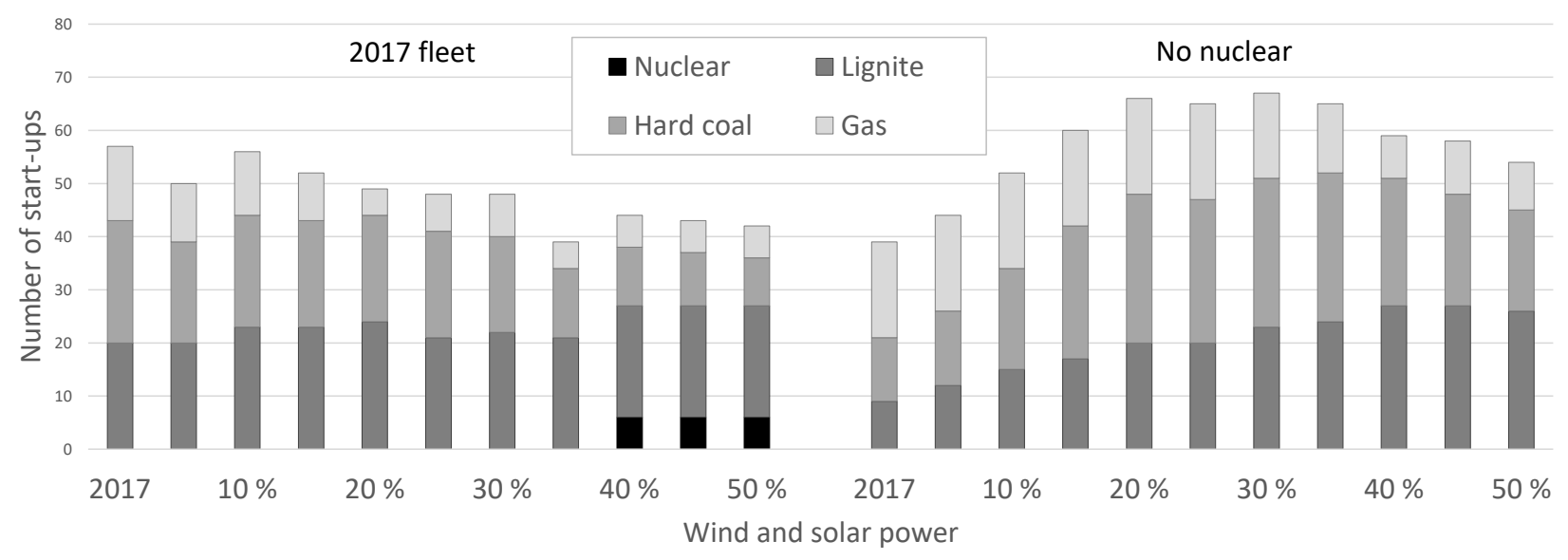

Omitting costly nuclear unit start-ups, the number of start-ups translates quite directly to the cost of the start-ups. This becomes evident when comparing Figure 3 to the right panel of Figure 4 (low demand week); both figures are based on the same scenario. Generally, the cost trajectories of the three representative weeks in Figure 4 suggest that the start-up costs increase with renewables. However, our model obviously underestimates the number of start-ups when the demand is high (as seen in Table B.1 in Appendix B). Particularly, the high demand week is subject to this bias. In the low demand week, when the solar and wind power supply increase by $40 \%$ of the year 2017 level, start-up costs increase rapidly in the "2017 fleet" since nuclear units are shut down for the first time.

Figure 4: Start-up costs with increasing wind and solar power supply in the two fleets in three representative weeks.

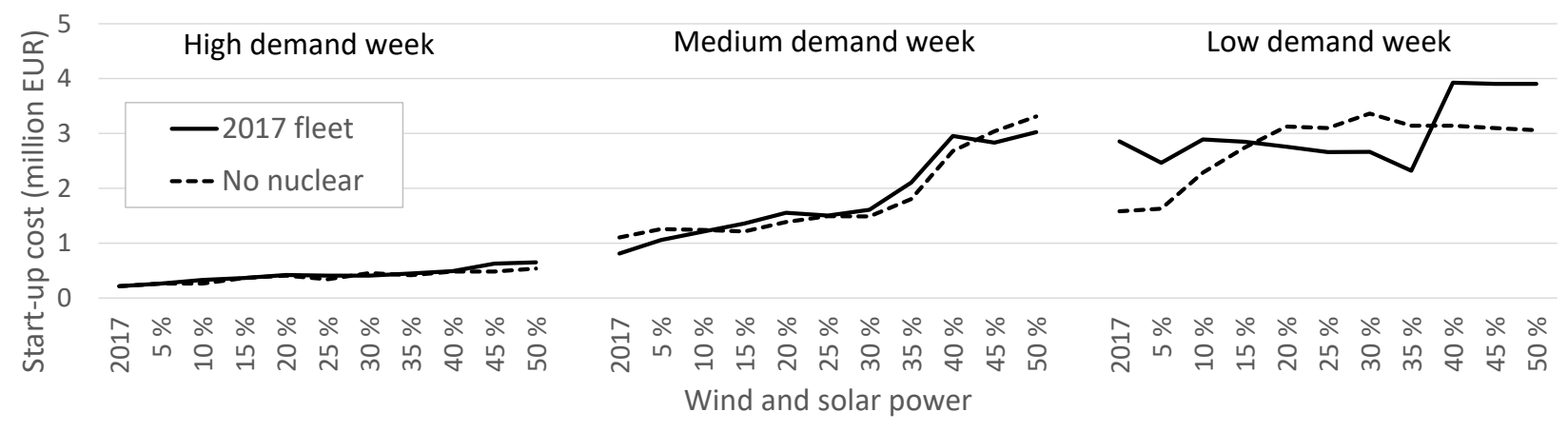




\subsection{Balancing costs}

In our model, the power plant portfolio, which is selected to provide balancing power when needed, depends on the market price and the characteristics of the plants. We find that the composition of this portfolio is quite sensitive to these factors. This can be seen in Figure 5, which presents the share of power plants (aggregated by fuel) that are selected for the secondary balancing reserve.

In the "2017 fleet" (the upper row in Figure 5), in high-demand situations, most balancing power is provided by the gas units because their marginal cost is close to the market price. This does not change much with increasing solar and wind. In the medium demand week, growing solar and wind power supply reduce the market price. As a result, nuclear and lignite units can provide balancing power at minimum cost. The more renewables there are, the more nuclear and lignite plants are selected for reserve. This effect reverses in the low demand week, when solar and wind power increase. Prices drop - even to a negative level -, which makes it increasingly costly to keep large nuclear and lignite units running in anticipation of providing spinning balancing power. Keeping gas units online is less expensive because of their lower nominal capacity per unit. Further, gas units can provide more balancing power (per unit of nominal capacity) than nuclear and lignite units because of their higher ramping rate. Therefore, gas units start replacing nuclear and lignite units again as the main balancing power providers with further increasing solar and wind power. A similar pattern of changes in the balancing power portfolio can be observed also when there are no nuclear units in the fleet (the lower row in Figure 5).

Figure 6 illustrates how balancing costs evolve with increasing solar and wind power supply. In the high demand week, capacity payments for the positive reserve make for the largest cost component in the total balancing costs. When the price is high, generating units receive high revenues in the spot market. Therefore, they require relatively high compensation for ramping down (to be able to provide positive balancing power when needed). When the price decreases with higher solar and wind power supply, the balancing costs decrease, too.

Balancing costs are lowest in the medium demand week, but perhaps the most striking feature in Figure 6 is that for both fleets, in the low demand week, balancing costs increase rapidly with renewables, and are multiple times higher than in the other two representative weeks. With an 
Figure 5: The shares of the balancing power providers by fuel type in the secondary reserve (both positive and negative reserve together) when solar and wind power supply increase.

- Nuclear $\quad$ Lignite $\quad \square$ Hard coal $\square$ Gas
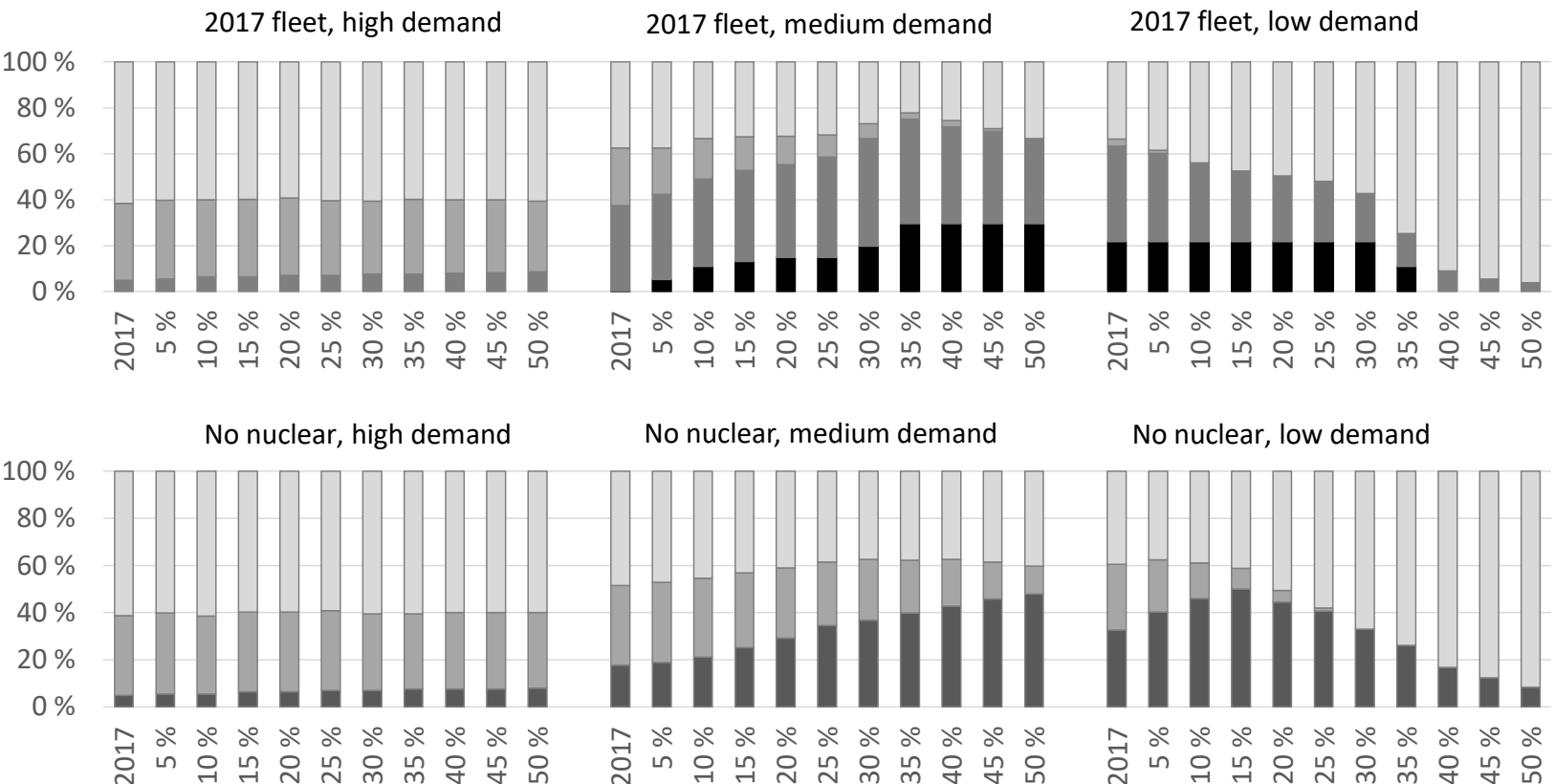

increasing share of solar and wind power, prices drop lower and lower, and the capacity payments for both the positive and negative reserve increase, since the units which provide balancing power have to be kept online, even if they make losses in the spot market. ${ }^{13}$

Since the differences in the two fleets in Figure 6 manifest mostly at the low marginal cost end, balancing costs for both fleets are very similar in the high and medium demand weeks. In the low demand week, balancing costs are higher for the fleet with nuclear units. This is driven by the technical characteristics of the nuclear units; the price is negative more frequently with nuclear units in a fleet (see Figures C.3 and C.5 in the supplementary material), and the (nominal) minimum load of a single nuclear unit is high. However, a single nuclear unit can provide balancing power on a large range.

\footnotetext{
${ }^{13}$ Kopiske et al. (2017) have similar results; if the German power plant fleet stays the same as in 2014, control reserve prices increase considerably by 2035. Also, Genoese et al. (2010) show that negative prices have likely contributed to the significant capacity price increases in the negative secondary reserve already in 2008 - 2009.
} 
Figure 6: Balancing power costs (both the secondary and minute reserve, and the capacity and energy payments together) when solar and wind power supply increase.

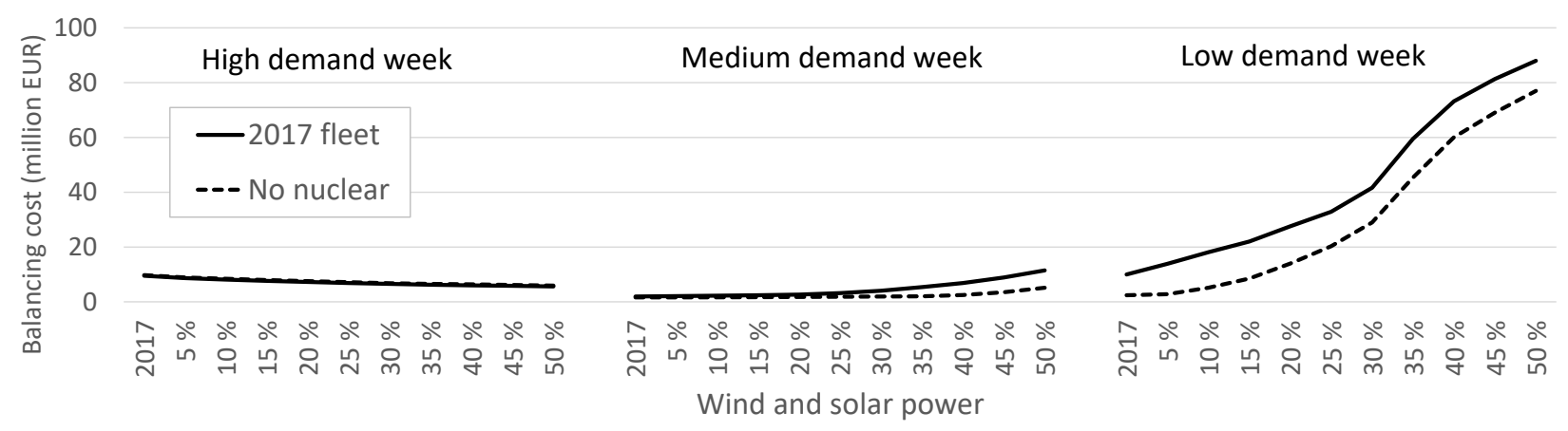

\subsection{Generation costs and total costs}

In contrast to start-up and balancing costs, generation costs of a conventional power plant fleet decrease with more renewables - less power is needed from the conventional units, and lowcost units are used relatively more. Still, generation costs are usually higher than start-up or balancing costs. Figure 7 shows the three cost components per all generated MWh in the low demand week. Generation costs decrease when the share of renewables grows (zero generation cost is assumed for solar and wind power). Start-up costs are negligible in all scenarios, but total balancing costs grow rapidly with renewables, and can be significantly high with high wind and solar power supply. As balancing costs increase faster than generation costs decrease, the net effect of increasing renewables is an increase in costs in the low demand week.

Since nuclear units have low variable costs, generation costs are lower for a fleet with nuclear units (here: the "2017 fleet") but on the other hand, balancing costs in this scenario are higher. The generation costs dominate this trade-off; and accounting for all three cost components, total costs are lower when the fleet has nuclear units in all investigated scenarios in the low demand week: in Figure 7, the left bar ("2017 fleet") is below the right bar ("No nuclear") at all solar and wind power supply levels.

In what follows, we use the term total costs to denote the sum of the three cost components, namely generation, start-up, and balancing costs. Figure 8 shows total costs and generation costs for each of the three representative weeks. Again, the total costs before the nuclear phase-out ("2017 fleet") are lower than after the phase-out ("No nuclear") in all scenarios. Therefore, one of 
Figure 7: The three cost components in the low demand week with increasing wind and solar power supply. Costs are in euros per MWh generated by the conventional power plants or renewables.

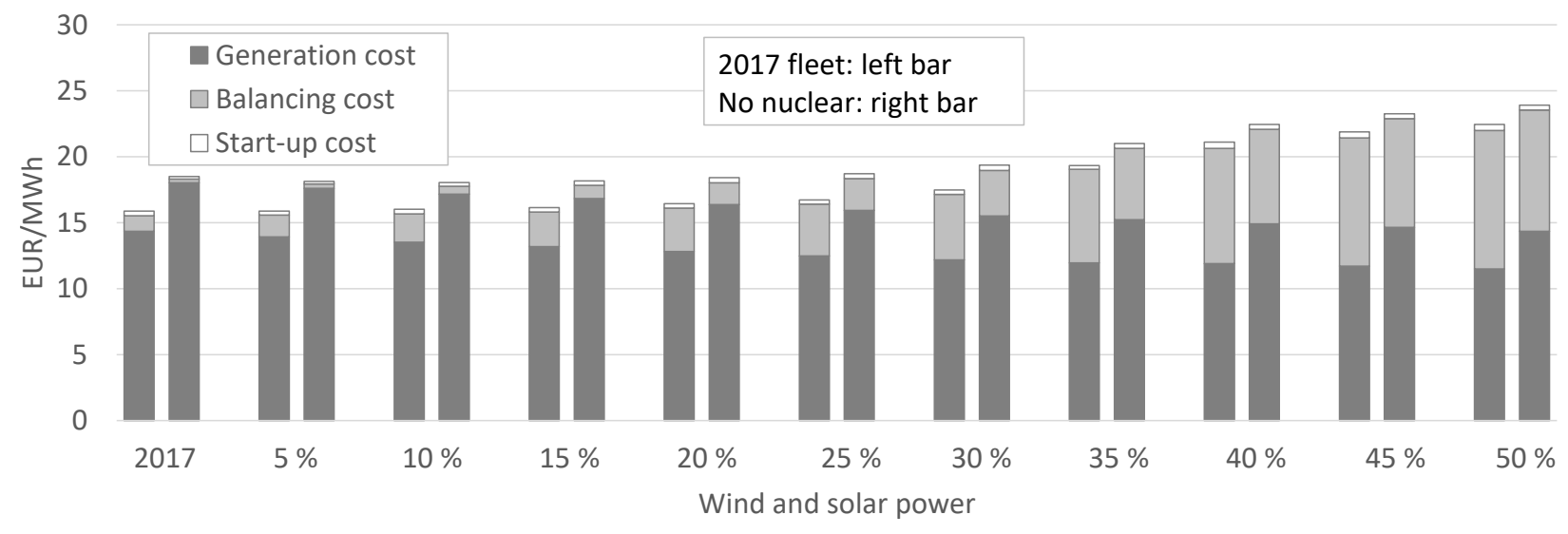

our main findings in this study is that the lower balancing costs in the fleet without nuclear units do not outweigh the lower generation costs of the nuclear units when up to $50 \%$ additional solar and wind power is assumed. ${ }^{14}$

Figure 8: Total costs (solid lines) and generation costs (dashed lines) with increasing wind and solar power supply (note that the graphs are stacked - the generation costs are part of the total costs).

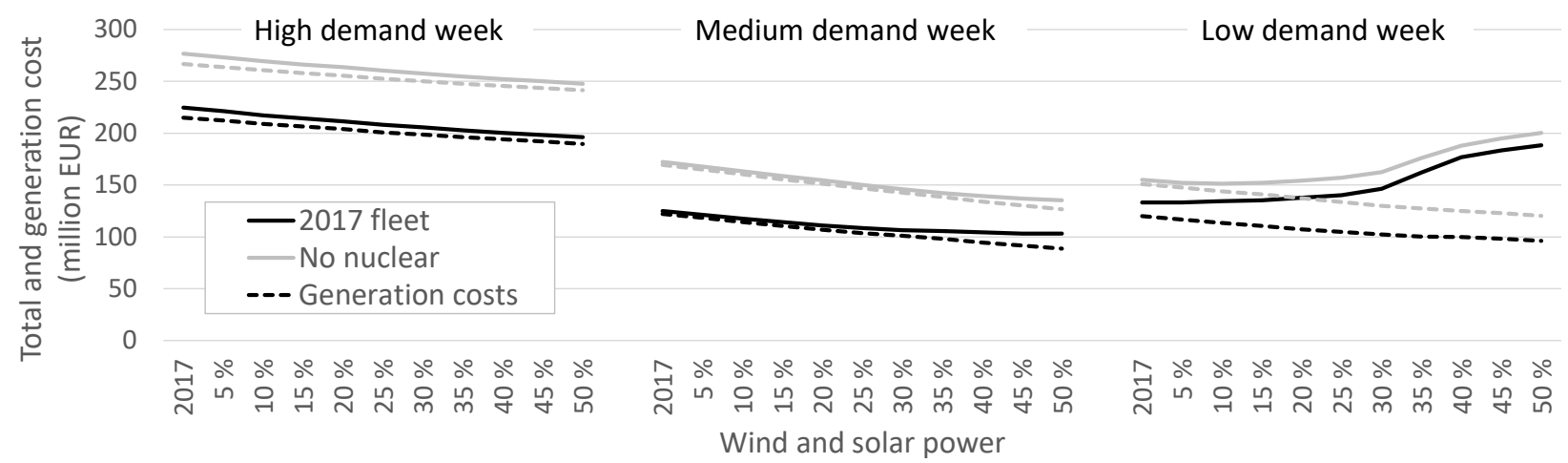

\subsection{Annual costs}

In the sections above, we reported the costs solely for the three representative weeks. When solar and wind power increase, the costs in the representative weeks are affected, but this increase

\footnotetext{
${ }^{14}$ The decreasing difference in the graphs suggests that, at some point, the total costs in the "No nuclear" fleet would reach the costs in the "2017 fleet" when renewables increase further. Our simulations show that this would happen approximately at $75 \%$ more solar and wind.
} 
will also affect the frequency of those representative weeks. Particularly, there will be relatively more low demand weeks and less high demand weeks. To account for this, we summarize our analysis by presenting the costs occurring across one entire year in Figure 9. In this figure, the simulations are done similarly to our prior analyses, but by using data from the entire year 2017 .

Figure 9 shows that balancing costs have an important role also in an annual scope when solar and wind power increase, while the share for start-up costs still remains very low. In all studied scenarios, total costs are lower with nuclear units in the fleet, even if the balancing costs are higher. When renewables increase by $25 \%$, decreasing generating costs compensate for increasing balancing costs in both fleets, with total costs being at the same level ("2017 fleet") or lower ("No nuclear" fleet). But when an additional share of $50 \%$ of renewables is assumed, balancing costs increase faster than generation costs decrease, increasing total costs to a level higher than that of the 2017 solar and wind level.

Table 1 provides a more detailed cost breakdown for two renewable penetration levels. To highlight some findings, the average capacity factor for nuclear units decreases from $98 \%$ to $86 \%$ with $50 \%$ more renewables. A $86 \%$ capacity factor is not particularly low for nuclear power plants, and should be sufficient to keep them profitable in the long-run. ${ }^{15}$ At the year 2017 observed solar and wind penetration level, balancing costs are dominated by the costs in the positive reserve, but when adding $50 \%$ more renewables, the negative reserve becomes more expensive. ${ }^{16}$ When the level of residual demand for the conventional units decreases, low-cost

\footnotetext{
${ }^{15}$ In our simulations, at the year 2017 level, there are no nuclear start-ups during the year, and the nuclear units are ramped down to below $35 \%$ of their nominal power on average 10 times per unit. With $50 \%$ more renewables, nuclear units have, on average, 23 shutdowns per unit per year, and 64 ramps (the range varies from 21 to 103 across units) to a $35 \%$ level. Thus, the technical constraints described in Section 2 are not binding in the examined range of renewable power.

${ }^{16}$ Recall that we consider only the spinning reserve in our analysis. Stand-by reserves, which are not running before requested to provide positive balancing power, are typically able to participate only in the minute reserve. Most of these units are gas-fired. Omitting the stand-by units in the positive minute reserve should not affect our energy payment estimates in the balancing market, since bids both in the spinning and stand-by reserve should be based on variable costs. Instead, it may upward bias our capacity payment estimates for the positive balancing power in the minute reserve. "Non-spinning" units do not need to cover the costs of generating at a minimum load, so they are
} 
Figure 9: Annual total costs (per all generated energy) and their components for the two different fleets with increasing solar and wind power.

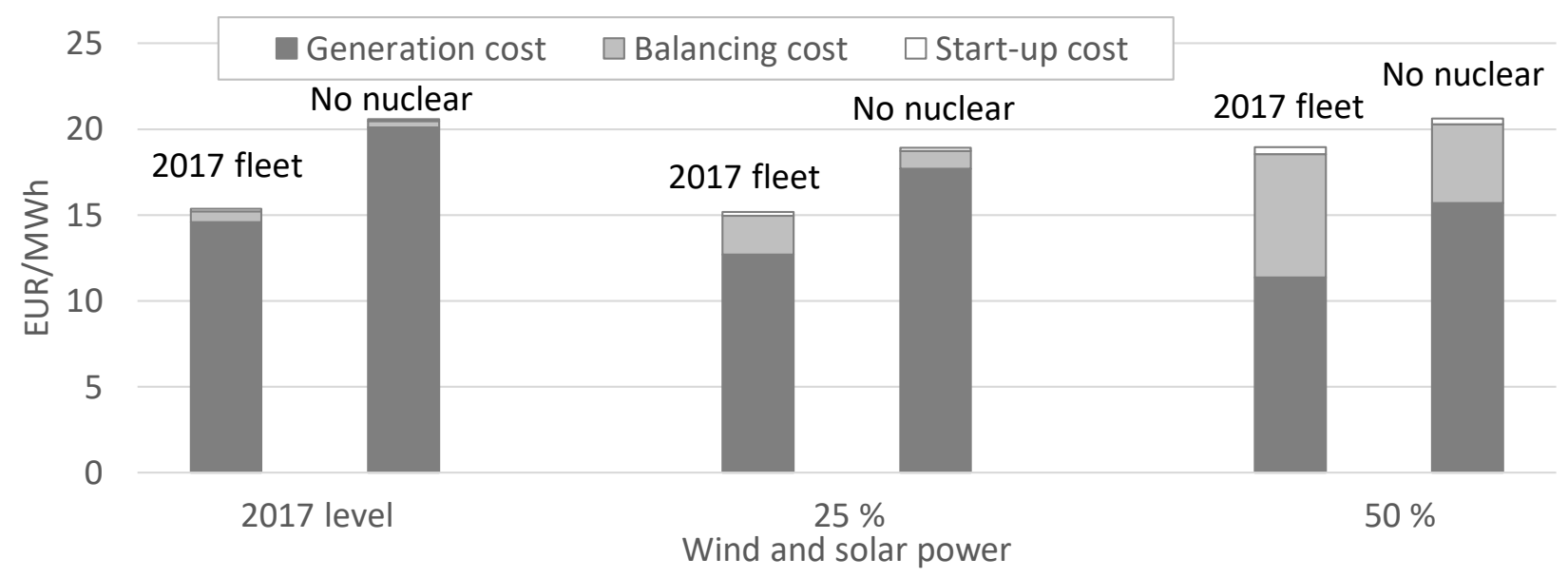

units are used relatively more. Distributing generation costs over the generation of conventional units reveals that this reduces generation costs only very little.

We also report ramping cost estimates in Table 1. They are not included in the cost minimization problem (Equation (6)), but calculated ex-post from the resulting generation changes. We assume a ramping cost of 0.7 EUR per changed MW for gas units, and 1.5 EUR / ramped MW for all other units. ${ }^{17}$ Ramping costs are smaller without nuclear because gas units are ramped more. Still, the ramping costs are quite modest, with $1.2-2.0 \%$ of the total costs and $9-21 \%$ of the start-up costs. If ramping costs were included in the optimization, some savings in ramping costs could be achieved by ramping up gas units instead of coal or nuclear; but most likely, these savings would be outweighed by higher generation costs.

\subsection{Sensitivity analysis}

Finally, we investigate how sensitive the costs are to changes in the power plant units' technical characteristics (see Table C.1 in the supplementary material). Specifically, we compare the following four fleets to the previous two:

likely able to submit lower capacity bids than the spinning reserve units. However, the negative reserve is responsible for most of the balancing costs when renewables increase (see Table 1); and of all positive capacity payments, the minute reserve comprises $8-33 \%$ in our simulations (less when there are more renewables).

${ }^{17}$ Schröder et al. (2013) suggest 0.25 - 1.17 EUR / MW for gas units and 1.3 - 1.7 EUR / MW for coal units. 
Table 1: The breakdown of the annual costs with year 2017 solar and wind power supply and $50 \%$ more.

\begin{tabular}{|c|c|c|c|c|}
\hline \multirow{2}{*}{$\begin{array}{l}\text { Solar and wind power supply } \\
\text { Fleet }\end{array}$} & \multicolumn{2}{|c|}{2017 level } & \multicolumn{2}{|c|}{$50 \%$ more } \\
\hline & 2017 fleet & No nuclear & 2017 fleet & No nuclear \\
\hline Generation cost (mEUR) & 6117.4 & 8433.9 & 4771.6 & 6580.2 \\
\hline Nuclear capacity factor ${ }^{a}$ & 0.98 & - & 0.86 & - \\
\hline Solar and wind curtailment (\%) & 0.0 & 0.0 & 1.1 & 1.0 \\
\hline Start-up cost (mEUR) & 65.0 & 48.8 & 177.2 & 141.5 \\
\hline Number of start-ups & 1404 & 1283 & 2592 & 3041 \\
\hline Ramping cost (mEUR) ${ }^{b}$ & 11.1 & 10.4 & 15.7 & 15.2 \\
\hline Gas unit ramps (\%) & 12.5 & 20.5 & 11.9 & 17.4 \\
\hline Balancing cost (mEUR) & 268.1 & 156.2 & 3006.0 & 1933.7 \\
\hline Positive reserve & 199.4 & 143.3 & 949.0 & 605.5 \\
\hline Negative reserve & 68.7 & 12.9 & 2057.0 & 1328.2 \\
\hline Total cost (mEUR) & 6450.4 & 8638.9 & 7954.8 & 8655.4 \\
\hline Generation cost (EUR/MWh) & 14.57 & 20.09 & 11.37 & 15.68 \\
\hline per conventional generation & 20.48 & 28.23 & 19.81 & 27.35 \\
\hline Start-up cost (EUR/MWh) & 0.15 & 0.12 & 0.42 & 0.34 \\
\hline Balancing cost (EUR/MWh) & 0.64 & 0.37 & 7.16 & 4.61 \\
\hline Total cost (EUR/MWh) & 15.37 & 20.58 & 18.95 & 20.62 \\
\hline
\end{tabular}

${ }^{a}$ Planned maintenance breaks are not accounted for.

${ }^{\mathrm{b}}$ Ramping costs are not included in total costs. 
1. Flexible coal. The same as the "No nuclear" fleet, but all coal-fired units (both lignite and hard coal) have the same ramping rate and minimum load as the gas units. This fleet could also be interpreted as the German conventional fleet after the potential coal phase-out (see Climate Analytics (2018) and Schrader (2016)).

2. Min load $10 \%$. The same as the "2017 fleet", but the nuclear units' minimum load is lowered to $10 \%$ (previously at $30 \%$ ).

3. Ramp $5 \%$. The same as the "2017 fleet", but the nuclear units' ramping rate is increased to $5 \%$ (previously at $1-1.6 \%$ ).

4. Min load + ramp. The same as the "2017 fleet", but the minimum load is set to $10 \%$ and the ramping rate is set to $5 \%$.

The cost components are presented in Figure 10, for two levels of intermittent renewables. At the 2017 solar and wind power level (left panel), changes in the technical parameters do not affect total costs substantially, but with $50 \%$ more renewables (right panel), there are significant differences in costs.

If coal-fired units were more flexible, balancing costs would decrease, and the total costs without nuclear (the "Flexible coal" fleet) would be approximately at the same level as in the "2017 fleet". Thus, relatively big changes in the coal units' flexibility would be required to compensate for their higher generation costs, compared to nuclear units. As expected, increasing the ramping rate and decreasing the minimum load reduces both start-up and balancing costs. The higher ramping rate affects the balancing costs relatively more, while the lower minimum load mainly affects start-up costs. The improvements seem to be independent of each other in the sense that improving both at the same time leads to further savings.

\subsection{Economic curtailing}

So far, we have considered solar and wind power supply as strictly exogenous; they are accepted in the grid whenever available, and conventional power plants need to adapt to their fluctuations. Since increasing solar and wind power supply increase balancing and start-up costs on a market-level, it may sometimes be economical to curtail some of this supply, even if the generation 
Figure 10: Sensitivity of costs to changes in technical parameters.

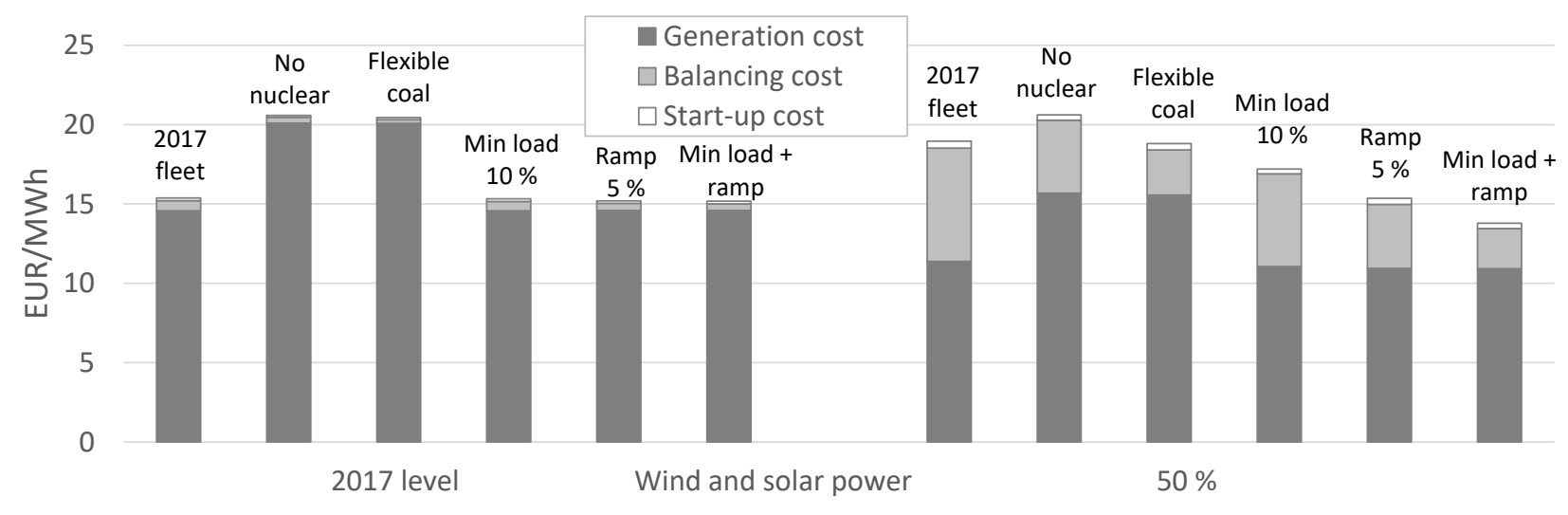

costs of solar and wind power are practically zero (Bird et al. (2016)). We discuss this along with including renewables in the balancing reserve in the supplementary material, C.2.

\section{Conclusions and policy implications}

In this article, we examine whether the comparatively low flexibility of nuclear power plants - stemming from the technical characteristics of the plants and the commitments in the balancing market - is hindering the deployment of fluctuating solar and wind power in Germany by incurring additional costs, or whether the lower variable costs of the nuclear units is outweighing this lower flexibility. We build a model incorporating both the electricity market and the balancing market, and study quantitatively how the planned nuclear phase-out in Germany in 2022 will affect the costs of integrating increasing amounts of fluctuating renewables in the German power market. Specifically, we focus on three cost components, namely start-up costs, balancing costs, and generation costs, and investigate how they evolve in a German conventional power plant fleet, with and without nuclear units, when the share of renewables grows. We omit any other changes in the market to isolate the interaction between the nuclear fleet and the renewables.

We find that, in Germany, the low flexibility of nuclear power plants is not an economic obstacle for the planned deployment of intermittent renewables in the near future. Start-up and balancing costs are higher with nuclear units in the fleet, but they are outweighed by the nuclear units' lower generation costs until the share of renewables increases notably. According to our simulations, the nuclear phase-out in 2022 increases costs in the electricity and the balancing market 
together by at least $9 \%$ (700 million EUR). Solar and wind power capacity should almost double from the level in 2017 (this is anticipated by 2030) before it will be cost-efficient to decommission the nuclear units from the fleet.

Our main finding is that the balancing market is the most important source of an increase in costs when the share of solar and wind power grows. If power plants place their bids in the balancing market according to their electricity market based opportunity costs, balancing costs will increase rapidly already in the near future, since low and negative prices will likely occur more frequently in the electricity market. This cost growth is further accelerated if balancing needs increase with renewables, and more balancing power is procured. Importantly, with the current flexibility in the conventional fleet, balancing costs increase faster than the growing share of solar and wind power reduces total generation costs. Technical developments in the conventional power plants would efficiently reduce balancing costs. Furthermore, our results confirm previous findings in existing literature about start-up costs being negligible even with relatively high solar and wind penetration. Still, start-ups do not increase proportionally with renewables, which is due to balancing market commitments. Overall, our results show that it is important to take into account interactions between the electricity market and the balancing market when examining the costs arising from integrating more renewables.

Our findings imply several policy recommendations: 1) If solely considering costs, it would be efficient to postpone the nuclear phase-out by some years, until more solar and wind power is deployed. Our simulations suggest that with the current target deployment path for renewables, the optimal timing for the nuclear phase-out would be somewhere near 2027. 2) It would be advantageous to introduce economic curtailing for excess solar and wind power already at the current level of solar and wind power to prevent low negative prices. Alternatively, accepting solar and wind power in the negative balance reserve offers a promising way to lower the total costs in the two markets substantially. 3) Investing in efforts to increase the technical flexibility of nuclear power plants could be beneficial. However, it might require new economic incentives that account for the entire market-level costs to harness the full flexibility potential of the nuclear units, and to encourage further technical improvement.

We apply our model specifically to the German power market; and the quantitative results 
cannot be generalized to other markets as such - the numerical results depend on the marketspecific features such as the power plant portfolio, demand pattern, interconnections, renewable profile, etc. Still, the identified dependencies, interactions, and the resulting conclusions in this study are relevant also for other markets. Another limitation is that we calibrate the model with existing data, but extend the analysis to the future. Especially in times with very high solar and wind power supply, future behaviour is hard to derive and anticipate from current data.

An interesting avenue for the future research is to examine how new emerging technologies particularly utility-scale storage and demand response - affect the costs of the conventional power plant fleet and the whole market. Also, our model could be applied to study the cost-efficient way to introduce solar and wind power in the balancing market, or to implement economic curtailing. Economic incentives for encouraging increasing flexibility of power plants could be analyzed as well, but we leave this up to future work.

\section{Acknowledgements}

The author is grateful to Florian Kühnlenz, two anonymous reviewers for advice and suggestions, and Bianca Beyer for proofreading. All remaining errors are my own. This study is funded by Tauno Tönning Foundation and the Strategic Research Council, Finland, Project No. 292854. 


\section{References}

Bird, L., Lew, D., Milligan, M., Carlini, E. M., Estanqueiro, A., Flynn, D., Gomez-Lazaro, E., Holttinen, H., Menemenlis, N., Orths, A., Eriksen, P. B., Smith, J. C., Soder, L., Sorensen, P., Altiparmakis, A., Yasuda, Y., Miller, J., 2016. Wind and solar energy curtailment: A review of international experience. Renewable and Sustainable Energy Reviews 65, 577-586.

BMWi, 2017a. Renewable energy sources in figures, national and international development, 2017. https:// www . bmwi.de/Redaktion/EN/Publikationen/renewable-energy-sources-in-figures-2017.html, Accessed: 2019-03-24.

BMWi, 2017b. Renewable energy sources act (EEG 2017). https://www.bmwi.de/Redaktion/EN/Downloads/ renewable-energy-sources-act-2017.pdf, Accessed: 2019-03-24.

BNetzA, 2017. Monitoring report 2017. https://www.bundesnetzagentur.de/EN/Areas/Energy/ Companies/DataCollection_Monitoring/Archived\%20Data/Archived_data-node.html, Accessed: 2019-03-24.

Bruninx, K., Madzharov, D., Delarue, E., D’haeseleer, W., 2013. Impact of the German nuclear phase-out on Europe's electricity generation - A comprehensive study. Energy Policy 60, 251-261.

Bruynooghe, C., Eriksson, A., Fulli, G., 2010. Load-following operating mode at nuclear power plants (NPPs) and incidence on operation and maintenance (O\&M) costs. Compatibility with wind power variability. JRC Scientific and Technical Reports No. EUR 24583 EN, Institute for Energy, Joint Research Centre, European Commission.

Cany, C., Mansilla, C., Mathonnière, G., da Costa, P., 2018. Nuclear power supply: Going against the misconceptions. Evidence of nuclear flexibility from the French experience. Energy 151, 289-296.

Climate Analytics, 2018. Science based coal phase-out pathway for Germany in line with the Paris agreement 1.5C warning limit: Opportunities and benefits of accelerated energy transition. www.climateanalytics.org/ publications.

Denholm, P., Hand, M., 2011. Grid flexibility and storage required to achieve very high penetration of variable renewable electricity. Energy Policy 39, 1817-1830.

ENTSO-E, 2017a. Total load. https ://transparency.entsoe.eu/load-domain/r2/totalLoadR2/show, Accessed: 2019-03-24.

ENTSO-E, 2017b. Actual generation per production type. https ://transparency . entsoe.eu/generation/r2/ actualGenerationPerProductionType/show, Accessed: 2019-03-24.

ENTSO-E, 2017c. Cross-border physical flow. https://transparency.entsoe.eu/transmission-domain/ physicalFlow/show, Accessed: 2019-03-24.

ENTSO-E, 2017d. Accepted offers and activated balancing reserves. https://transparency.entsoe.eu/ $\mathrm{bal}$ ancing/r2/activationAndActivatedBalancingReserves/show, Accessed: 2019-03-24.

ENTSO-E, 2017e. Actual generation per generation unit. https ://transparency .entsoe.eu/generation/r2/ 
actualGenerationPerGenerationUnit/show, Accessed: 2019-03-24.

EPEX, 2017a. EPEX SPOT market data, day-ahead auction. https://www.epexspot.com/en/market-data/ dayaheadauction, Accessed: 2019-03-24.

Fursch, M., Lindenberger, D., Malischek, R., Nagl, S., Panke, T., Truby, J., 2012. German nuclear policy reconsidered: Implications for the electricity market. Economics of Energy \& Environmental Policy 1 (3), 39-58.

Genoese, F., Genoese, M., Wietschel, M., 2010. Occurrence of negative prices on the German spot market for electricity and their influence on balancing power markets. In: EEM2010 - 7th International Conference on the European Energy Market. pp. 1-6.

Hirth, L., Ziegenhagen, I., 2015. Balancing power and variable renewables: Three links. Renewable and Sustainable Energy Reviews 50, 1035-1051.

Holttinen, H., Meibom, P., Orths, A., Lange, B., O’Malley, M., Tande, J. O., Estanqueiro, A., Gomez, E., Söder, L., Strbac, G., Smith, J. C., van Hulle, F., 2011. Impacts of large amounts of wind power on design and operation of power systems, results of IEA collaboration. Wind Energy 14 (2), 179-192.

Huber, M., Dimkova, D., Hamacher, T., 2014. Integration of wind and solar power in europe: Assesment of flexibility requirements. Energy 69, 236-246.

IAEA, 2018. Non-baseload operation in nuclear power plants: Load following and frequency control modes of flexible operation. IAEA Nuclear Energy Series No. NP-T-3.23, International Atomic Energy Agency (IAEA).

Jenkins, J., Zhou, Z., Ponciroli, R., Vilim, R., Ganda, F., de Sisternes, F., Botterud, A., 2018. The benefits of nuclear flexibility in power system operations with renewable energy. Applied Energy 222, 872-884.

Just, S., Weber, C., 2015. Strategic behavior in the German balancing energy mechanism: Incentives, evidence, costs and solutions. Journal of Regulatory Economics 48 (2), 218-243.

Kondziella, H., Bruckner, T., 2016. Flexibility requirements of renewable energy based electricity systems - a review of research results and methodologies. Renewable and Sustainable Energy Reviews 53, 10-22.

Kopiske, J., Spieker, S., Tsatsaronis, G., 2017. Value of power plant flexibility in power systems with high shares of variable renewables: A scenario outlook for Germany 2035. Energy 137, 823-833.

Kunz, F., Weigt, H., 2014. Germany's nuclear phase out - A survey of the impact since 2011 and outlook to 2023. Economics of Energy \& Environmental Policy 3 (2), 13-28.

Lechtenböhmer, S., Samadi, S., 2013. Blown by the wind. Replacing nuclear power in German electricity generation. Environmental Science \& Policy 25, 234-241.

Lew, D., Brinkman, G., Ibanez, E., Florita, A., Heaney, M., Hodge, B.-M., Hummon, M., Stark, G., King, J., Lefton, S., Kumar, N., Agan, D., Jordan, G., Venkataraman, S., 2013. The Western wind and solar integration study phase 2. Technical report, NREL/TP-5500-55588, NREL, National Renewable Energy Laboratory.

Ludwig, H., Salnikova, T., Stockman, A., Waas, U., 2010. Load cycling capacilities of German nuclear power plants (NPP). International Journal for Nuclear Power 55 (8/9). 
Lund, P. D., Lindgren, J., Mikkola, J., Salpakari, J., 2015. Review of energy system flexibility measures to enable high levels of variable renewable electricity. Renewable and Sustainable Energy Reviews 45, 785-807.

Ma, J., Silva, V., Belhomme, R., Kirschen, D. S., Ochoa, L. F., 2013. Evaluating and planning flexibility in sustainable power systems. In: 2013 IEEE Power Energy Society General Meeting. pp. 1-11.

Müsgens, F., Ockenfels, A., Peek, M., 2014. Economics and design of balancing power markets in Germany. Electrical Power and Energy Systems 55, 392-401.

NEA, 2011. Technical and economic aspects of load following with nuclear power plants. Technical report, Nuclear Energy Agency (NEA), OECD.

Newbery, D. M., Greve, T., 2017. The strategic robustness of oligopoly electricity market models. Energy Economics 68, 124-132.

Ocker, F., Ehrhart, K.-M., 2017. The "German paradox" in the balancing power markets. Renewable and Sustainable Energy Reviews 67, 892-898.

Palchak, D., Denholm, P., 2014. Impact of generator flexibility on electric system costs and integration of renewable energy. Technical report, NREL/TP-6A20-62275, NREL, National Renewable Energy Laboratory.

Pérez-Arriaga, I., Batlle, C., 2012. Impacts of intermittent renewables on electricity generation system operation. Economics of Energy \& Environmental Policy 1, 3-18.

Regelleistung.net, 2017a. Pre-qualified balancing capacity. https://www.regelleistung.net/ext/download/ pq_capacity, Accessed: 2019-03-24.

Regelleistung.net, 2017b. Balancing reserve tender details. https://www.regelleistung.net/ext/tender/, Accessed: 2019-03-24.

Schill, W.-P., 2014. Residual load, renewable surplus generation and storage requirements in Germany. Energy Policy $73,65-79$.

Schill, W.-P., Pahle, M., Gambardella, C., 2017. Start-up costs of thermal power plants in markets with increasing shares of variable renewable generation. Nature Energy 2, article number 17050.

Schrader, C., 2016. Can Germany engineer a coal exit? Science 351 (6272), 430-431.

Schröder, A., Kunz, F., Meiss, J., Mendelevitch, R., von Hirschhausen, C., 2013. Current and prospective costs of electricity generation until 2050. DIW Berlin Data Documentation nr. 68, DIW Berlin.

Troy, N., Denny, E., O’Malley, M., 2010. Base-load cycling on a system with significant wind penetration. IEEE Transactions on Power Systems 25 (2).

Turvey, R., 2006. Interconnector economics. Energy Policy 34, 1457-1472. 


\section{Appendix A. Computational details}

We formulate the cost minimization problem (Equation (6)) in the spot market as a mixed integer linear programming problem and solve it using Matlab and CPLEX. Solving this nonconvex optimization problem is still time- and memory-consuming if there are many units and time periods ( $J$ and $H$ are large). But if the time horizon in the optimization $(H)$ is too short, the solution can deviate remarkably from the optimum in the longer run.

We tackle this computational challenge using a moving time window where time periods represent varying numbers of hours. This is illustrated in Figure A.1. We always solve the optimization problem $(6)$ for 48 time periods $(H=48)$. The first 24 time periods represent single hours and contain hourly residual demand, but for the following 12 time periods, we use the average residual demand over 4 hours. Correspondingly, for the last 12 time periods, we calculate the average demand over 6 hours. So, regarding the demand, the foresight is perfect for the first 24 hours, and more vague for the subsequent days. This allows us to cover six full days when solving the optimization problem once. Even if hourly variations in demand are lost in the last days of this window, larger variations are still accounted for. This method also reflects the fact that predicting demand and solar and wind power supply is more accurate for the hours in the near future than for more distant hours.

When solving the unit-specific generation schedule for one week, we first solve the schedule for the 48 time periods starting from the first hour of the week. Then, we shift the time window one hour forward and solve the following 48 time periods using the previously solved hour as an initial status for the generating units (which units are running and which need to be started up if generating). This is repeated 168 times to obtain the generation schedule for one full week. So, in practice, the generation quantities are solved several times for each hour but with increasingly accurate information about the past and future. In the endpoints (the beginning of the week and the end of the week), we use the least-cost solution for a single hour as an initial condition for the first hour of the week, and also as an assumption for the following hour after the last hour of the week. 
Figure A.1: Solving the unit commitment problem using a moving window.

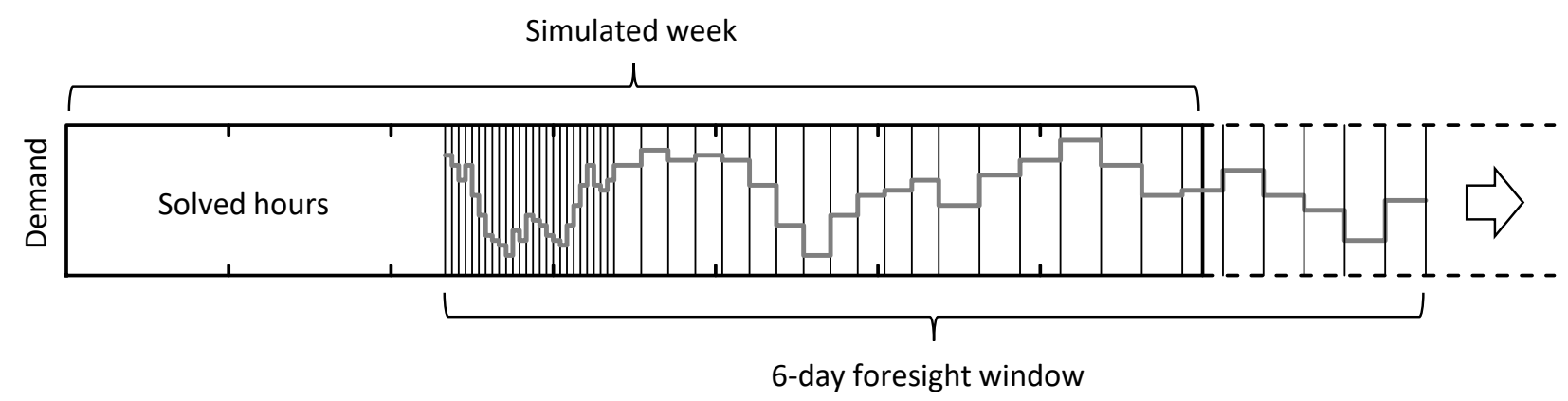

\section{Appendix B. Model fit}

Generally, our model can explain well the nuclear units' observed generation at low- and negative-price hours. Regarding the start-ups, the model does not perform as well. Table B.1 compares the number of start-ups in the three representative weeks. In the low demand week, our simulation has 58 start-ups in total, while 66 start-ups occurred in reality. Ignoring start-up costs fully in the simulation would lead to 129 start-ups. So, in the low demand week, the EEX market result was close to the simulated least-cost schedule. Interestingly, this is not the case in the high demand week. In that week, 95 start-ups were realized, while our least-cost solution proposes only four. Many start-ups could have been avoided if the units were dispatched centrally (like in our model). Probably ownership structures and imperfect competition explain part of this difference. Thus, even though our sample size is very small, our results suggest that the current EEX market finds the least-cost solution more likely at low demand than when the demand is high. ${ }^{18}$

Figure B.1 compares realized (solid lines) and simulated (dashed line) aggregate bid curves in the positive secondary balancing reserve on one day in the low demand week. ${ }^{19}$ Capacity payments are allocated using a pay-as-bid auction. This may explain why the realized capacity bids are higher in the middle (the left panel); firms want to maximize their revenue by bidding as

\footnotetext{
${ }^{18}$ This result contributes to the literature examining whether complex bids are more cost-effective in a market with a high amount of variable renewables, or whether block bids (like in EEX) are sufficient to account for generation units' dynamic costs. See, e.g., the discussion in Troy et al. (2010).

${ }^{19}$ Aggregate bid curves in the German balancing market are available in Regelleistung.net (2017b). For simplicity, we use only one product in the simulation instead of separate peak and off-peak products.
} 
Table B.1: Number of start-ups in the three representative weeks. Realized values and the simulated least cost solution.

\begin{tabular}{|c|c|c|c|c|c|c|}
\hline & \multicolumn{2}{|c|}{ Low demand week } & \multicolumn{2}{|c|}{ Medium demand week } & \multicolumn{2}{|c|}{ High demand week } \\
\hline & Realized & Least-cost & Realized & Least-cost & Realized & Least-cos \\
\hline Nuclear & 0 & 0 & 0 & 0 & 1 & 0 \\
\hline Lignite & 12 & 18 & 6 & 7 & 6 & 0 \\
\hline Hard coal & 28 & 21 & 44 & 11 & 24 & 0 \\
\hline Gas & 26 & 19 & 45 & 2 & 64 & 4 \\
\hline Number of start-ups & 66 & 58 & 95 & 20 & 95 & 4 \\
\hline Start-up cost (mEUR) & 3.60 & 2.63 & 5.43 & 1.03 & 4.07 & 0.26 \\
\hline Share of total cost (\%) & 2.8 & 2.1 & 3.6 & 0.8 & 1.7 & 0.1 \\
\hline
\end{tabular}

close to the marginal bidder as possible. Our model assumes that both capacity and energy bids are set competitively, and firms do not take into account the expected values of other bids. Therefore, this inflation of bids is not present in our capacity bid curve making it less flat than the realized curves. $^{20}$

It is apparent from the shape of the capacity bid curve in the left panel of Figure B.1 that capacity payments are quite sensitive to the amount of procured balancing capacity. In our simulations, we find that if ten percent more balancing capacity is procured, the balancing costs increase by 12 - $18 \%$ (depending on solar and wind penetration, less when the share of solar and wind power is higher). If the procured capacity is doubled, balancing costs will be 2.5 - 3.8 times higher. The fleet without nuclear is slightly more sensitive; doubling the procured capacity makes the costs 2.6 - 3.9 times higher.

The right panel of Figure B.1 illustrates energy bids. Realized energy bids are about four times higher than our simulated bids. Strategic behaviour can explain this partially (see Just and Weber (2015) and Ocker and Ehrhart (2017)), but generally, it means that our estimates for energy payments in the balancing market are clearly too low.

\footnotetext{
${ }^{20}$ Using a different methodology, the simulations in Kopiske et al. (2017) also result in prices that are lower than the historical data (4 - $16 \%$ lower average control reserve prices in the secondary reserve, and $54-60 \%$ lower in the minute reserve). They explain that with imperfect competition in the market.
} 
Figure B.1: Aggregated capacity and energy bid curves in the positive secondary reserve on 27.4.2017.
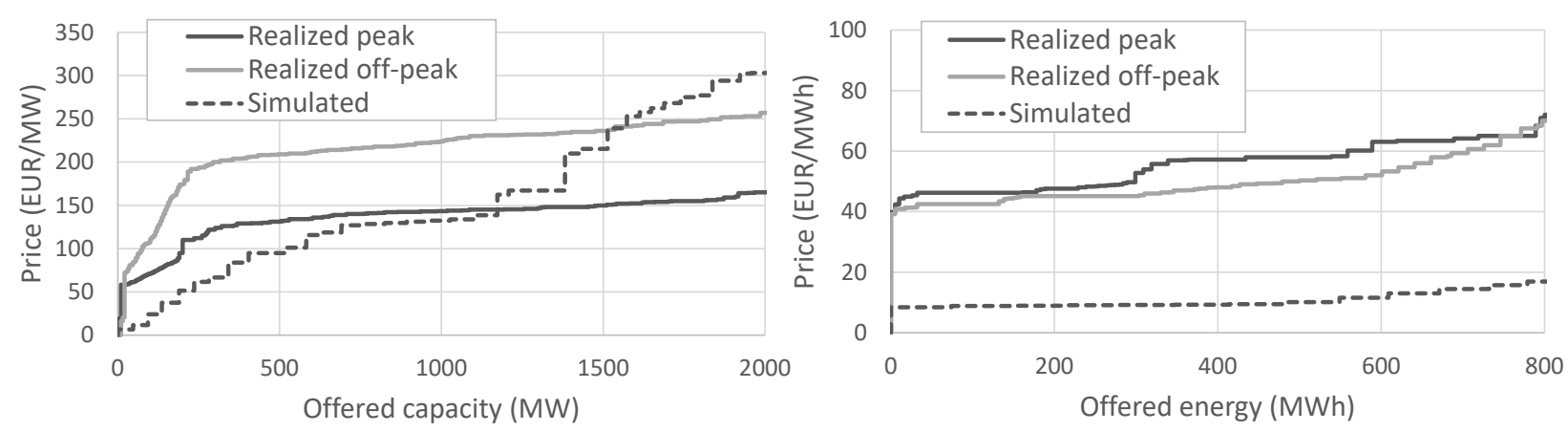